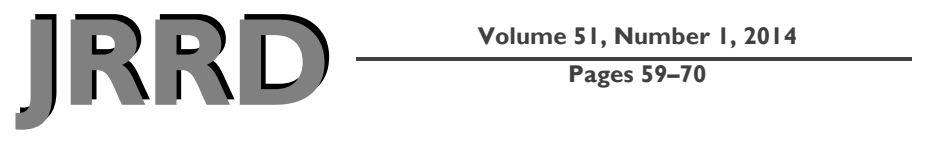

\title{
Cognitive Symptom Management and Rehabilitation Therapy (CogSMART) for Veterans with traumatic brain injury: Pilot randomized controlled trial
}

\author{
Elizabeth W. Twamley, PhD; ${ }^{1-2 *}$ Amy J. Jak, PhD; ${ }^{1-3}$ Dean C. Delis, PhD; ${ }^{1}$ Mark W. Bondi, PhD; ${ }^{2-3}$ James B. \\ Lohr, MD ${ }^{1-2}$ \\ ${ }^{1}$ Center of Excellence for Stress and Mental Health, Department of Veterans Affairs (VA) San Diego Healthcare System, \\ San Diego, CA; ${ }^{2}$ Department of Psychiatry, University of California, San Diego, San Diego, CA; ${ }^{3}$ Psychology Service, VA \\ San Diego Healthcare System, San Diego, CA
}

\begin{abstract}
Traumatic brain injury (TBI) can result in cognitive impairments and persistent postconcussive symptoms that limit functional recovery, including return to work. We evaluated a 12 wk compensatory cognitive training intervention (Cognitive Symptom Management and Rehabilitation Therapy [CogSMART]) in the context of supported employment for Veterans with mild to moderate TBI. Participants were randomly assigned to receive $12 \mathrm{wk}$ of supported employment plus CogSMART or enhanced supported employment that controlled for therapist attention (control). CogSMART sessions were delivered by the employment specialist and included psychoeducation regarding TBI; strategies to improve sleep, fatigue, headaches, and tension; and compensatory cognitive strategies in the domains of prospective memory, attention, learning and memory, and executive functioning. Compared with controls, those assigned to supported employment plus CogSMART demonstrated significant reductions in postconcussive symptoms (Cohen $d=0.97$ ) and improvements in prospective memory functioning (Cohen $d=0.72$ ). Effect sizes favoring CogSMART for posttraumatic stress disorder symptom severity, depressive symptom severity, and attainment of competitive work within 14 wk were in the small to medium range (Cohen $d=0.35-0.49$ ). Those who received CogSMART rated the intervention highly. Results suggest that adding CogSMART to supported employment may improve postconcussive symptoms and prospective memory. These effects, as well as smaller effects on psychiatric symptoms and ability to return to work, warrant replication in a larger trial.
\end{abstract}

Key words: attention, brain injury, cognitive rehabilitation, cognitive training, depression, employment, executive functioning, memory, postconcussive symptoms, posttraumatic stress disorder, rehabilitation, unemployment.

\section{INTRODUCTION}

Traumatic brain injury (TBI) is considered the signature wound among Veterans of Operation Iraqi Freedom (OIF) and Operation Enduring Freedom (OEF), mainly because of the large numbers of blast injuries caused by improvised explosive devices [1]. The vast majority of these TBIs (89\%) are in the mild or moderate range [1], with estimates that approximately 20 percent of OIF/OEF

Abbreviations: CAPS = Clinician-Administered Posttraumatic Stress Disorder Scale, CogSMART = Cognitive Symptom Management and Rehabilitation Therapy, CVLT-II = California Verbal Learning Test-2nd edition, D-KEFS = Delis-Kaplan Executive Function System, DOD = Department of Defense, HAM-D = Hamilton Depression Rating Scale, IQ = intelligence quotient, IRB = Institutional Review Board, LOC = loss of consciousness, MIST = Memory for Intentions Screening Test, NSI = Neurobehavioral Symptom Inventory, OEF = Operation Enduring Freedom, OIF = Operation Iraqi Freedom, PTSD = posttraumatic stress disorder, TBI = traumatic brain injury, VA = Department of Veterans Affairs.

*Address all correspondence to Elizabeth W. Twamley, PhD; Center of Excellence for Stress and Mental Health, VA San Diego Healthcare System, 3350 La Jolla Village Dr (116A), San Diego, CA 92161; 858-642-3848; fax: 858-6421243. Email: etwamley@ucsd.edu

http://dx.doi.org/10.1682/JRRD.2013.01.0020 
Veterans have sustained a mild TBI [2-3]. Numerous studies demonstrate that individuals with mild to moderate TBI exhibit problems with concentration, learning and memory, prospective memory (remembering to do things in the future), and problem solving [4-8], all of which can limit functional recovery, including cognitive readiness for work and school [9-10]. However, there has been scant research on cognitive rehabilitation for individuals with mild to moderate TBI.

Studies show that neurocognitive functioning is strongly associated with employment status across a variety of disorders (e.g., human immunodeficiency virus, epilepsy, and psychiatric disorders), including TBI, with effect sizes in the medium range (executive functioning: $d=0.62$, learning and memory: $d=0.61$, and attention/ concentration: $d=0.53$ [11]). Difficulty learning job tasks, distractibility, or slowness in job performance, for example, can lead to job failures, and cognitive abilities among those with TBI histories have been shown to predict functional skills and ability to work [12-14].

In addition, recent data show that about 7 percent of OIF/OEF Veterans who use Department of Veterans Affairs (VA) healthcare have persistent postconcussive symptoms such as difficulties with cognitive functioning, sleep, fatigue, emotional functioning, and headaches [15]. Healthcare costs and service utilization rates are greater in these Veterans, possibly because of high rates of comorbidities such as posttraumatic stress disorder (PTSD) (comorbid in 73\%); depression (47\%); and back, neck, and/or headache pain (72\%) [15]. These comorbidities can also further contribute to cognitive impairment [4,1617]. Thus, a need exists for interventions to improve cognition and functioning of these individuals. There are no known medications that correct the cognitive deficits of TBI. Given the extraordinary plasticity of the human brain [18], cognition must be considered one of the most promising targets for improvement via psychological methods.

Cognitive training is a rehabilitative technique that has been used in TBI, psychiatric disorders [19-21], and memory disorders such as Alzheimer disease [22]. The research on cognitive training interventions has examined both restorative and compensatory approaches to treatment [23]. Restorative interventions aim to restore cognitive abilities via drills and practice, whereas compensatory interventions teach clients strategies to work around their cognitive deficits, using alternative ways to carry out daily living activities. Compensatory strategies may be internal (e.g., using acronyms to remember information) or external (e.g., using a calendar, alarms, or smartphones to remember activities). Although there have been numerous studies of cognitive rehabilitation in TBI [24-25], most published TBI rehabilitation research has involved people with severe TBI, and little is known about rehabilitation for those with mild to moderate TBI [26]. There has been only one randomized controlled trial of comprehensive cognitive rehabilitation therapy in a group with mild to moderate TBI with chronic symptoms (i.e., patients whose injuries occurred more than 6 mo before treatment [27]), which is the population most similar to OIF/OEF Veterans with TBI histories presenting for care at VA facilities. As a result of the limited high-quality research available, the VA/Department of Defense (DOD) Clinical Practice Guideline for Management of Concussion/Mild TBI [28] does not make recommendations in favor of or against compensatory training or training on the use of external memory aids; it does, however, emphasize psychoeducation and family education regarding TBI, as well as functional and vocational interventions to promote community reintegration [28].

Based on our reviews of prior cognitive training studies [19-20,22], we developed a manualized, $12 \mathrm{wk}$, multimodal compensatory cognitive training intervention emphasizing habit learning and compensatory strategies in prospective memory, attention, learning and memory, and executive functioning. The treatment manual was informed by consultation with the acquired brain injury program at Mesa College in San Diego, California, and other cognitive remediation experts. The compensatory cognitive training intervention has demonstrated efficacy in improving cognition, psychiatric symptoms, functional capacity, and quality of life in people with severe mental illness [29]. The compensatory cognitive training manual was subsequently adapted for Veterans with mild to moderate TBI; consistent with the Clinical Practice Guideline [28], sections on psychoeducation regarding TBI and strategies to improve postconcussive symptoms (sleep disturbance, fatigue, headaches, and tension) were added, and the entire manual was rewritten to be applicable to Veterans with TBI. Prospective memory, or memory for intentions, continued to be highlighted because it is one of the most frequent sequelae of TBI and because of its obvious implications for treatment adherence [30]. The resulting intervention, Cognitive Symptom Management and Rehabilitation Therapy (CogSMART), is portable, practical, and designed to be implemented without extensive training. CogSMART can be delivered to individuals or groups, in the clinic or in the community, increasing the potential for training gains to transfer into the real-world 
environment. CogSMART encourages the involvement of family or other support persons in the first two and last two sessions of the intervention, so that family members can learn about TBI, generate a plan for supporting the patient's use of new strategies, give feedback about the effectiveness of strategy use, and plan for further application of the strategies to daily life activities. Table 1 lists the CogSMART modules and examples of strategies taught.

Meta-analytic studies of cognitive rehabilitation for severe mental illness have shown that cognitive interventions lead to better outcomes when they are embedded in a broader psychosocial rehabilitation program [20-21], and the Clinical Practice Guideline recommended vocational interventions to improve community integration [28]. Furthermore, compensatory strategies have been used successfully within the context of supported employment for individuals with TBI [31]. Thus, we chose to evaluate the efficacy of CogSMART within the context of an evidencebased supported employment program. Supported employment is a cost-effective, evidence-based, individualized approach to work rehabilitation emphasizing rapid job searching for competitive work in the community, based on client interests and preferences [9,32]. Augmenting work rehabilitation with compensatory cognitive training may improve functional outcomes because compensatory interventions can be individualized and tailored to each person's job search process and job duties.

In our pilot study, all participants received supported employment for 1 yr. During the first 3 mo of the study, participants were randomized to also receive CogSMART or additional supported employment sessions (enhanced supported employment). We hypothesized that, compared with enhanced supported employment, supported employment plus CogSMART would result in reductions in postconcussive symptoms (primary outcome), improvements in cognition and functional capacity, and better rates of job placement at postintervention. In this article, we present the baseline and postintervention data; future reports will address the durability of CogSMART effects and its longer-term effects on work outcomes over $1 \mathrm{yr}$.

\section{METHODS}

\section{Participants}

Fifty Veterans receiving healthcare at the VA San Diego Healthcare System enrolled in the study and gave their written informed consent prior to study participation.

Table 1.

Domains targeted in Cognitive Symptom Management and Rehabilitation Therapy (CogSMART) and their associated strategies.

\begin{tabular}{|c|c|}
\hline Impaired Domain & Specific Compensatory Strategies and Habits Taught in CogSMART \\
\hline \multirow[t]{4}{*}{ Postconcussive Symptoms } & Psychoeducation regarding natural course of postconcussive symptoms. \\
\hline & Appropriate pacing, use of routines, and lifestyle strategies. \\
\hline & $\begin{array}{l}\text { Stress reduction (e.g., progressive muscle relaxation, abdominal breathing, mindfulness, visualization, } \\
\text { grounding). }\end{array}$ \\
\hline & $\begin{array}{l}\text { Sleep hygiene education; headache management; and education regarding depression, anxiety, and } \\
\text { posttraumatic stress disorder. }\end{array}$ \\
\hline \multirow[t]{3}{*}{ Prospective Memory } & Daily calendar use. \\
\hline & To-do lists and prioritizing tasks. \\
\hline & Linking tasks and using “can’t miss reminders” to cue tasks. \\
\hline \multirow[t]{2}{*}{ Attention and Vigilance } & Conversational vigilance skills (reduce distractions, eye contact, paraphrasing, and asking questions). \\
\hline & Task vigilance skills (paraphrase instructions, use self-talk during tasks to maintain focus). \\
\hline \multirow[t]{2}{*}{ Learning and Memory } & $\begin{array}{l}\text { Encoding strategies (write things down, paraphrasing/repetition, association, chunking, categorizing, } \\
\text { acronyms, rhymes, visual imagery, name-learning strategies). }\end{array}$ \\
\hline & $\begin{array}{l}\text { Retrieval strategies (systematic searching) and organizational strategies for general learning and } \\
\text { memory. }\end{array}$ \\
\hline \multirow[t]{3}{*}{ Executive Functioning } & $\begin{array}{l}\text { 6-step problem-solving method (define problem, brainstorm solutions, evaluate solutions, select } \\
\text { solution, try it, evaluate how it worked). }\end{array}$ \\
\hline & Self-talk while solving problems. \\
\hline & Hypothesis testing and self-monitoring. \\
\hline
\end{tabular}


Inclusion criteria were (1) OIF/OEF Veteran; (2) history of mild to moderate TBI (loss of consciousness [LOC] $<6 \mathrm{~h}$; posttraumatic amnesia $<7 \mathrm{~d}$ ) according to the Clinical Practice Guideline [28], documented in a prior clinical neuropsychological evaluation and confirmed by a structured interview; (3) documented impairment ( $>1$ standard deviation below the mean) in at least one neuropsychological domain (i.e., attention, processing speed, working memory, learning, memory, executive functioning), as determined by valid clinical neuropsychological testing by a VA or DOD neuropsychologist using at least one effort test (e.g., Test of Memory Malingering, California Verbal Learning Test-2nd edition [CVLT-II] Forced Choice); and (4) unemployed, but stating a goal of work. Veterans who met criteria for current alcohol and/or substance abuse or dependence or who were participating in other intervention studies were excluded. Eight participants dropped out, four from each group (two decided not to pursue work, one moved, and five were lost to followup). Posttreatment data were available for 34 participants at 3 mo (16 in supported employment plus CogSMART [3 with moderate $\mathrm{TBI}$ ] and 18 in enhanced supported employment [4 with moderate TBI]). The 34 participants with complete baseline and posttreatment data did not differ on age, education level, sex, race, ethnicity, premorbid intelligence quotient (IQ), length of LOC during their worst TBI, or length of total LOC summed across up to four TBIs (all $p>0.13$ ) from the 16 participants who did not have a 3 mo assessment. On average, the 34 participants with complete data were $32 \mathrm{yr}$ old, had $13.6 \mathrm{yr}$ of education, were 94 percent male, and were 76 percent members of a racial or ethnic minority group; 76 percent met criteria for threshold PTSD [33]. The median length of LOC for the worst TBI was $1.5 \mathrm{~min}$, and 82 percent of these injuries were contact TBIs (vs blast only); the median length of total LOCs summed across up to four TBIs was $1.7 \mathrm{~min}$. Table 2 presents sample characteristics by group. The treatment groups did not differ by sex, race, ethnicity, postconcussive and psychiatric symptom severity, presence of mild or greater depressive symptoms, presence of threshold PTSD, TBI severity (length of LOC in the worst TBI and summed across up to 4 TBIs), years since their most recent TBI, nature of their worst TBI (contact vs blast only), or years since their worst TBI (all $p \geq 0.06$ ). The group that received supported employment plus CogSMART, however, was about 5 yr younger on average than the group that received enhanced supported employment $(p=0.05)$.

\section{Procedure}

Study referrals came from the VA San Diego Healthcare System Wellness and Vocational Enrichment Clinic, TBI Cognitive Rehabilitation Clinic, Polytrauma Clinic, and Neuropsychological Assessment Unit. Participants were compensated $\$ 20$ per assessment session but were not paid to participate in treatment.

Following baseline assessment, participants were randomized to one of two conditions: supported employment plus CogSMART or enhanced supported employment. Randomization was carried out by the principal investigator using a randomization scheme generated by Randomization.com, with 50 participants in one block. All Veterans in the study received supported employment for $1 \mathrm{yr}$, the goal of which is competitive employment. Two supported employment specialists provided all services; one employment specialist delivered CogSMART for $1 \mathrm{~h} / \mathrm{wk}$ in addition to standard supported employment (i.e., 2 visits/wk), and the other employment specialist delivered enhanced supported employment (2 visits/wk) to control for the nonspecific therapeutic factors provided in CogSMART. CogSMART and enhanced supported employment were provided during the first 12 wk of supported employment so that time and contact with the employment specialist were equivalent across groups. Consistent with the supported employment model, services were offered at locations of the participant's choosing (e.g., career center, home, coffee shop, library, or VA clinic). All participants received standard clinical care with their usual providers during the trial. CogSMART completion rates were high; 15 of the 16 participants randomized to receive supported employment plus CogSMART completed all 12 sessions, and 1 participant completed 8 sessions.

To ensure CogSMART treatment fidelity, all CogSMART sessions were audiotaped and 20 percent were randomly selected for fidelity rating every $2 \mathrm{wk}$. Adherence rates were consistently in the 90 to 100 percent range.

\section{Measures}

Measures were administered at baseline and 3 mo (i.e., following completion of the CogSMART or enhanced supported employment portion of the study). All tests were administered according to standardized procedures by a research assistant trained to a high level of interrater reliability (i.e., >0.90). The research assistant was not aware of participant randomization status at the baseline assessment but was aware of treatment group for subsequent assessments. 
Table 2.

Sample characteristics and differences between study groups at baseline assessment.

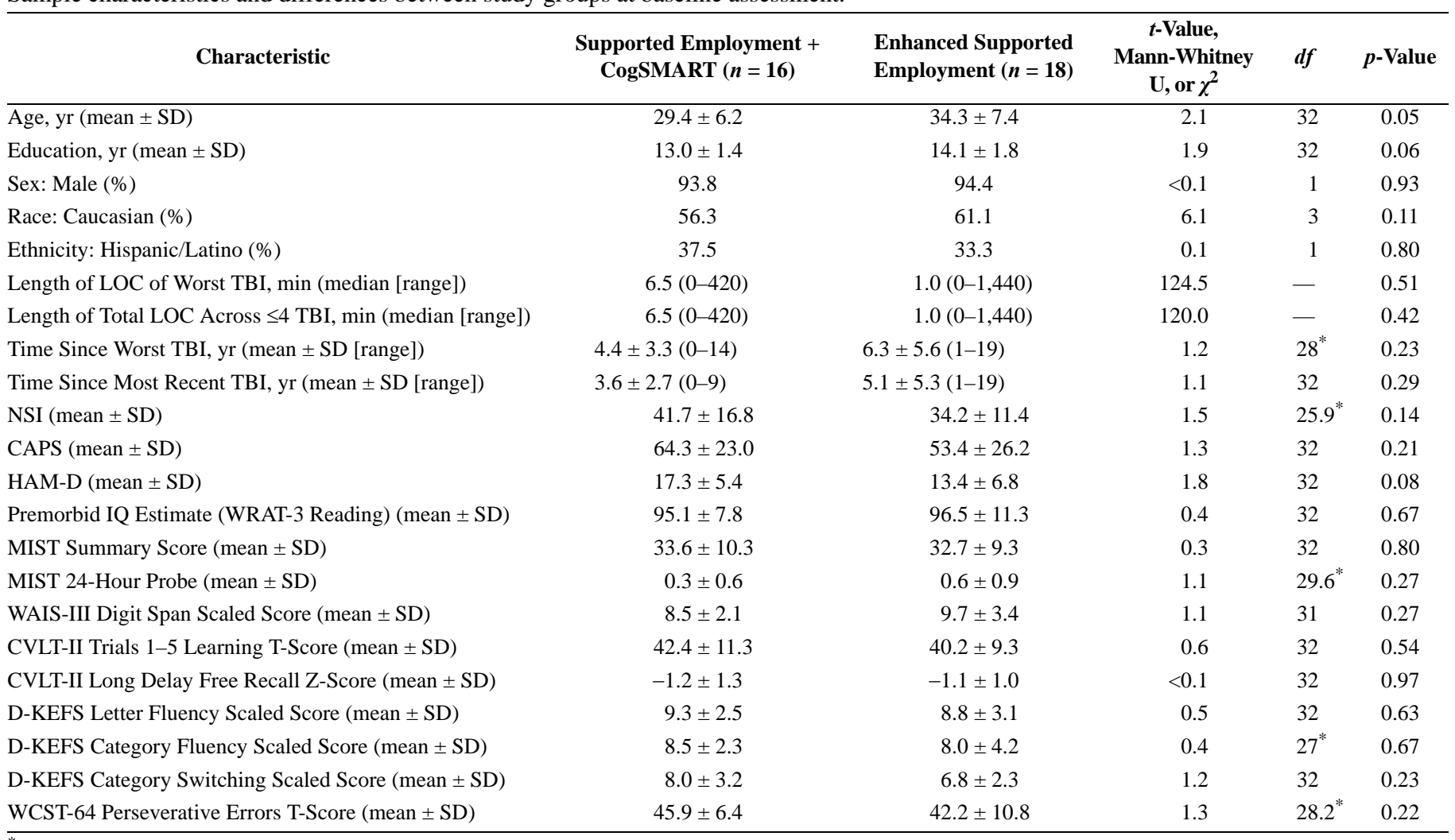

${ }^{*}$ Adjusted to unequal variances between groups.

CAPS = Clinician-Administered Posttraumatic Stress Disorder Scale, CogSMART = Cognitive Symptom Management and Rehabilitation Therapy, CVLT-II = California Verbal Learning Test-2nd edition, $d f$ = degrees of freedom, D-KEFS = Delis-Kaplan Executive Function System, HAM-D = Hamilton Depression Rating Scale, $\mathrm{IQ}=$ intelligence quotient, LOC = loss of consciousness, MIST = Memory for Intentions Screening Test, NSI = Neurobehavioral Symptom Inventory, SD = standard deviation, TBI = traumatic brain injury, WAIS-III = Wechsler Adult Intelligence Scale-3rd edition, WCST-64 = Wisconsin Card Sorting Test-64 card version, WRAT3 = Wide Range Achievement Test-3rd edition.

Measures of cognitive functioning were selected to appropriately characterize the sample and assess change in the four cognitive domains targeted by the CogSMART intervention (prospective memory, attention, learning and memory, and executive functioning), as follows:

1. Premorbid IQ was estimated with the Wide Range Achievement Test-3rd edition (WRAT-3) [34] Reading test, which requires the examinee to correctly pronounce irregularly spelled English words and was administered at baseline only because this ability was not expected to change over time. The age-corrected standard score is reported.

2. Prospective memory was measured with the Memory for Intentions Screening Test (MIST) [35], which requires examinees to perform directed actions at certain times or in response to specific cues. The MIST raw summary score is an index of short-term pro- spective memory ability during the 30 min test, and the $24 \mathrm{~h}$ raw probe score reflects long-term prospective memory ability over a $24 \mathrm{~h}$ period (the examinee is asked to call the examiner $24 \mathrm{~h}$ following the test to report how he or she slept).

3. Attention and working memory were measured with the Wechsler Adult Intelligence Scale-3rd Edition [36] Digit Span scaled score, which requires the examinee to repeat strings of digits in both forward and backward order.

4. Verbal learning and memory were measured with the CVLT-II [37]. The trials 1-5 T-score was used as an index of verbal learning and reflects acquisition of words over five learning trials. The long delay free recall Z-score was used to measure memory following a 20 min delay period. 
5. Executive functioning was measured with the DelisKaplan Executive Function System (D-KEFS) [38] Verbal Fluency test, which requires examinees to generate words beginning with a given letter (letter fluency) or belonging to a given category (category fluency) and to switch between words from two different categories (category switching); age-corrected scaled scores were used for these measures. The Wisconsin Card Sorting Test-64 card version [39] was also used to measure reasoning and set-switching; the perseverative errors T-score correcting for age and education was used.

Postconcussive symptom severity was measured with the Neurobehavioral Symptom Inventory (NSI) (a VA instrument developed following Cicerone and Kalmar [17]), which measures severity of self-reported cognitive, physical, and emotional symptoms on a 0 to 4 scale ranging from "none" to "very severe." There are 12 physical symptoms (e.g., dizziness, headaches, nausea, light and sound sensitivity), 4 cognitive symptoms (e.g., problems with concentration, memory, decision-making, slowed thinking), and 6 emotional symptoms (e.g., fatigue, sleep disturbance, anxiety, depression, irritability). PTSD symptom severity was measured with the Clinician-Administered PTSD Scale (CAPS) [40], the gold-standard interview to determine PTSD diagnosis and measure symptom severity. The CAPS total score symptom severity descriptors are 0-19= asymptomatic, 20-39 = mild/subthreshold, 40-59 = moderate/threshold, 60-79 = severe, and $\geq 80=$ extreme [33]. Depressive symptom severity was measured with the 17item Hamilton Depression Rating Scale (HAM-D) [41]. The HAM-D total score symptom severity descriptors are 0-7 = normal, 8-13 = mild, 14-18 = moderate, 19-22 = severe, and $\geq 23$ = very severe [41]. The Quality of Life Interview-Brief Version [42] assessed subjective judgment of global quality of life, rated by the participants on a 1 to 7 scale ranging from "terrible" to "delighted." Data regarding job attainment, hours worked, and wages earned were collected weekly. Participants randomized to the supported employment plus CogSMART condition rated the components of the CogSMART intervention on a scale from 1 to 5 ("not helpful" to "extremely helpful") and provided written qualitative comments following completion of the CogSMART sessions.

\section{Analyses}

Prior to the analyses, data were examined for missing values, statistical outliers, and normality. The LOC vari- ables were not normally distributed, so medians were used to characterize the sample. Differences between groups were analyzed with $t$-tests, Mann-Whitney $\mathrm{U}$ tests, and chi square tests. Although the treatment groups differed in age (Table 2), we did not adjust for this difference in our models because of the pilot nature of the study and the small sample size. Additionally, the age range in the two groups was similar (22-49 in the enhanced supported employment group and 22-44 in the supported employment plus CogSMART group). The outcome data were analyzed using $t$-tests between mean change scores in each group and chi square tests for work outcomes (attainment of competitive employment within $14 \mathrm{wk}$, which represented the average amount of time between the baseline and postintervention assessment). Secondary analyses removing the two oldest individuals in the enhanced supported employment group (which made the two groups not significantly different on age) did not change the results.

\section{RESULTS}

Independent samples $t$-tests on change scores between groups revealed significant CogSMART-associated improvements in postconcussive symptoms (NSI: $p=$ 0.01 ) and prospective memory performance (MIST $24 \mathrm{~h}$ probe: $p=0.05$ ) at posttreatment (Table 3). The Cohen $d$ effect sizes for these group differences between change scores were 0.97 and 0.72 , respectively. The remainder of the neuropsychological, symptom severity, quality of life, and work outcome comparisons did not reveal statistically significant differences between groups. However, the supported employment plus CogSMART group showed small to medium effect size improvements in psychiatric symptom severity (CAPS: $d=0.43$ and HAM-D: $d=0.37$, based on group differences between change scores) relative to the enhanced supported employment group. Five participants in the enhanced supported employment condition obtained competitive work within the first $14 \mathrm{wk}$ of the study compared with eight participants in the supported employment plus CogSMART condition $(d=$ 0.49) (Table 3).

Those who received CogSMART rated it highly with regard to helpfulness of information regarding TBI and postconcussive symptoms, information on PTSD, headache strategies, fatigue strategies, sleep strategies, prospective memory strategies, attention strategies, learning 
Table 3.

Comparisons of change in scores (posttreatment-baseline) and competitive work attainment between groups.

\begin{tabular}{|c|c|c|c|c|c|c|}
\hline Outcome Measure (mean \pm SD) & $\begin{array}{l}\text { Supported } \\
\text { Employment }+ \\
\text { CogSMART } \\
(n=16)\end{array}$ & $\begin{array}{l}\text { Enhanced } \\
\text { Supported } \\
\text { Employment } \\
\quad(n=18)\end{array}$ & $\begin{array}{l}t \text {-Value } \\
\text { or } \chi^{2}\end{array}$ & $d f$ & $p$-Value & Cohen $d$ \\
\hline MIST Summary Score & $4.9 \pm 7.1$ & $5.4 \pm 7.6$ & 0.2 & 31 & 0.83 & -0.08 \\
\hline MIST 24-Hour Probe & $0.1 \pm 0.7$ & $-0.5 \pm 0.9$ & 2.0 & 31 & 0.05 & 0.72 \\
\hline WAIS-III Digit Span Scaled Score & $0.0 \pm 1.5$ & $0.7 \pm 1.6$ & 1.2 & 31 & 0.23 & -0.43 \\
\hline CVLT-II Long Delay Free Recall Z-Score & $0.7 \pm 1.1$ & $0.8 \pm 1.0$ & 0.2 & 31 & 0.89 & 0.05 \\
\hline D-KEFS Letter Fluency Scaled Score & $0.6 \pm 3.4$ & $-0.2 \pm 2.4$ & 0.8 & 31 & 0.42 & 0.28 \\
\hline D-KEFS Category Fluency Scaled Score & $0.3 \pm 3.7$ & $-0.6 \pm 3.0$ & 0.8 & 31 & 0.42 & 0.28 \\
\hline D-KEFS Category Switching Scaled Score & $1.3 \pm 4.7$ & $0.7 \pm 2.6$ & 0.5 & 31 & 0.64 & 0.16 \\
\hline WCST-64 Perseverative Errors T-Score & $-0.1 \pm 4.9$ & $1.9 \pm 8.0$ & 0.9 & 31 & 0.40 & -0.30 \\
\hline QOLI-Brief & $0.3 \pm 1.0$ & $0.1 \pm 1.0$ & 0.6 & 31 & 0.55 & 0.21 \\
\hline Attained Competitive Work Within 14 wk (\%) & 50 & 26 & 2.1 & 1 & 0.15 & 0.49 \\
\hline \multicolumn{7}{|c|}{$\begin{array}{l}\text { Note: Cohen } d \text { values are positive if supported employment plus CogSMART group improved more than did enhanced supported employment group. } \\
\text { CAPS = Clinician-Administered Posttraumatic Stress Disorder Scale, CogSMART = Cognitive Symptom Management and Rehabilitation Therapy, CVLT-II = Cali- } \\
\text { fornia Verbal Learning Test-2nd edition, } d f=\text { degrees of freedom, D-KEFS = Delis-Kaplan Executive Function System, HAM-D = Hamilton Depression Rating } \\
\text { Scale, MIST = Memory for Intentions Screening Test, NSI = Neurobehavioral Symptom Inventory, QOLI-Brief = Quality of Life Interview-Brief Version, SD = stan- } \\
\text { dard deviation, WAIS-III = Wechsler Adult Intelligence Scale-3rd edition, WCST-64 = Wisconsin Card Sorting Test-64 card version. }\end{array}$} \\
\hline
\end{tabular}

and memory strategies, problem-solving strategies, and information regarding additional VA services (all means $\geq 3.5$ on a 5-point scale, where 3 = "moderately helpful" and 5 = "extremely helpful”). Prospective memory strategies received the highest mean rating (4.3), and many participants noted in their qualitative comments that they had begun using a calendar system (paper or smartphone). Sample comments from participants included-

- "I wish CogSMART was utilized while we were still in the service and that everyone had to go through it."

- "It has taken a lot of pressure off my wife because she doesn't have to keep up with my schedule and it has given me confidence to go to school."

- "It helped me relax, concentrate, and remember important things."

- "[The strategies helped me with] fixing my credit, staying on top of class work, and applying for competitive jobs.”

- "It helped me reduce stress greatly by having better organizational skills; I get better rest and it helps me concentrate.”
All CogSMART participants indicated that they would recommend CogSMART to other Veterans with similar problems.

\section{DISCUSSION}

We found that CogSMART, in the context of supported employment for Veterans with mild to moderate TBI, was associated with significant reductions in self-reported postconcussive symptoms and improvements in real-world prospective memory performance (the ability to carry out an assigned task $24 \mathrm{~h}$ later). There were also nonsignificant CogSMART-associated reductions in PTSD and depressive symptoms and return to competitive employment within 14 wk (all of which demonstrated small to medium effect sizes over 0.35). CogSMART participants rated the intervention as helpful and stated universally that they would recommend it to other Veterans. The high rate of comorbid PTSD (76\%) in our sample is not atypical in OIF/OEF Veterans with mild TBI [43]. The etiology of cognitive impairments in those with mild TBI and comorbid PTSD and/or depression appears mainly attributable to psychiatric 
comorbidity [44], and cognitive training approaches for those with both TBI and PTSD merit further research [43]. We want to emphasize that although CogSMART may have some modest effects on symptoms of PTSD and depression, these effects may overlap with those on postconcussive symptoms, and CogSMART is not a treatment for PTSD or depression.

The strengths of our study include its randomized design; robust control group; and use of both subjective, patient-centered outcome measures (e.g., self-reported postconcussive symptoms, psychiatric symptoms, and quality of life) and objective outcome measures (e.g., neuropsychological tests and competitive work outcomes). There were also several limitations to our study. First, this was a small pilot study that was affected by 16 percent dropout within the first 3 mo as well as missing data at the 3 mo assessment. Future analyses will use hierarchical linear modeling to fully take advantage of all data over the four assessments over the course of the study. The groups differed in age at baseline, which we elected not to control for in our analyses due to the small sample size and similar age range in both groups. However, the two groups did not differ on other symptom or injury characteristics, such as length of LOC or severity of postconcussive symptoms, cognitive impairment, or comorbid psychiatric symptoms. Outcome assessment was not blinded; however, most of our outcome measures were either objective (neuropsychological test performance, attainment of competitive work) or reported by the participant, rather than rated by the examiner. Therapist factors were a potential confound. We considered having a separate "cognitive specialist" deliver the CogSMART intervention instead of the employment specialist, but we believed the CogSMART intervention would be more efficacious in the context of supported employment as well as more cost-effective if delivered by one provider, which was necessarily the employment specialist. An advantage to this approach is that the employment specialist can continue to use and reinforce CogSMART principles throughout supported employment. We considered having the two employment specialists each provide services to participants in each study condition, but we opted to have one employment specialist affiliated with each treatment condition to prevent treatment contamination. Finally, our results may not generalize to individuals with severe TBI, people with TBI who do not want to work, or non-Veterans.

Future analyses will address the durability of CogSMART's effects over the course of the entire 12 mo study and will provide answers regarding whether
CogSMART-associated effects emerge later in the course of the study. We will also examine job acquisition, job tenure (weeks worked), and wages earned over the course of the study. In a separate study, we are also examining compensatory cognitive training as a group treatment for Veterans with TBI.

\section{CONCLUSIONS}

CogSMART is a 12 wk intervention to improve postconcussive symptoms (e.g., sleep disturbance, fatigue, headaches, and tension) and cognition in the domains of prospective memory, attention, learning and memory, and executive functioning. At this point, we tentatively conclude that CogSMART may improve postconcussive symptoms and prospective memory performance. Psychoeducation regarding TBI and postconcussive symptoms and training in compensatory strategies appear to be perceived by Veterans as helpful. Results of this pilot study are promising, but the CogSMART intervention needs to be studied in a larger trial.

\section{ACKNOWLEDGMENTS}

\section{Author Contributions:}

Study design: E. W. Twamley.

Data analysis: E. W. Twamley.

Data interpretation: E. W. Twamley, A. J. Jak, D. C. Delis, M. W. Bondi, J. B. Lohr.

Drafting of treatment manual: A. J. Jak.

Drafting of manuscript: E. W. Twamley.

Critical revision of manuscript for important intellectual content:

E. W. Twamley, A. J. Jak, D. C. Delis, M. W. Bondi, J. B. Lohr.

Financial Disclosures: Dr. Delis receives royalties from the sale of the CVLT-II and D-KEFS.

Funding/Support: This material was based on work supported by the DOD (award W81XWH-08-2-0193).

Additional Contributions: The authors acknowledge the assistance of Drs. Dewleen G. Baker and Rebecca E. Williams for their support of the study, the helpful consultation of Jennifer Vasterling and Paul Wehman, and the administrative support of Kelsey Thomas and Amber Gregory. They also thank Laurie Arnold, MS, CRC, for her work with our Veterans and recognize the previous contributions of Sarah K. Noonan, Gauri N. Savla, and Dawn Schiehser to the CogSMART treatment manual.

Institutional Review: This study was approved by the VA Rehabilitation Research and Development Institutional Review Board (IRB).

Participant Follow-Up: The authors have no plans to notify the study participants of the publication of this article because there were no plans for participant re-contact following study participation, thus re-contact was not approved by the IRB. 


\section{REFERENCES}

1. Fischer H; Library of Congress, Congressional Research Service. United States military casualty statistics: Operation Iraqi Freedom and Operation Enduring Freedom. Washington (DC): Congressional Research Service, Library of Congress; 2007.

2. Hoge CW, McGurk D, Thomas JL, Cox AL, Engel CC, Castro CA. Mild traumatic brain injury in U.S. Soldiers returning from Iraq. N Engl J Med. 2008;358(5):453-63.

[PMID:18234750] http://dx.doi.org/10.1056/NEJMoa072972

3. Tanielian TL, Jaycox L; RAND Corporation. Invisible wounds of war: Psychological and cognitive injuries, their consequences, and services to assist recovery. Santa Monica (CA): RAND Center for Military Health Policy Research; 2008.

4. Binder LM. Persisting symptoms after mild head injury: A review of the postconcussive syndrome. J Clin Exp Neuropsychol. 1986;8(4):323-46. [PMID:3091631] http://dx.doi.org/10.1080/01688638608401325

5. Kinsella G, Murtagh D, Landry A, Homfray K, Hammond M, O’Beirne L, Dwyer L, Lamont M, Ponsford J. Everyday memory following traumatic brain injury. Brain Inj. 1996; 10(7):499-507. [PMID:8806010]

http://dx.doi.org/10.1080/026990596124214

6. Vanderploeg RD, Crowell TA, Curtiss G. Verbal learning and memory deficits in traumatic brain injury: encoding, consolidation, and retrieval. J Clin Exp Neuropsychol. 2001;23(2):185-95. [PMID:11309672]

http://dx.doi.org/10.1076/jcen.23.2.185.1210

7. Vanderploeg RD, Curtiss G, Belanger HG. Long-term neuropsychological outcomes following mild traumatic brain injury. J Int Neuropsychol Soc. 2005;11(3):228-36.

[PMID:15892899] http://dx.doi.org/10.1017/S1355617705050289

8. Belanger HG, Curtiss G, Demery JA, Lebowitz BK, Vanderploeg RD. Factors moderating neuropsychological outcomes following mild traumatic brain injury: A meta-analysis. J Int Neuropsychol Soc. 2005;11(3):215-27. [PMID:15892898] http://dx.doi.org/10.1017/S1355617705050277

9. Wehman P, Targett P, West M, Kregel J. Productive work and employment for persons with traumatic brain injury: What have we learned after 20 years? J Head Trauma Rehabil. 2005;20(2):115-27. [PMID:15803036] http://dx.doi.org/10.1097/00001199-200503000-00001

10. Dawson DR, Schwartz ML, Winocur G, Stuss DT. Return to productivity following traumatic brain injury: cognitive, psychological, physical, spiritual, and environmental correlates. Disabil Rehabil. 2007;29(4):301-13.

[PMID:17364780]

http://dx.doi.org/10.1080/09638280600756687
11. Kalechstein AD, Newton TF, van Gorp WG. Neurocognitive functioning is associated with employment status: A quantitative review. J Clin Exp Neuropsychol. 2003;25(8): 1186-91. [PMID:14566590] http://dx.doi.org/10.1076/jcen.25.8.1186.16723

12. Leahy BJ, Lam CS. Neuropsychological testing and functional outcome for individuals with traumatic brain injury. Brain Inj. 1998;12(12):1025-35. [PMID:9876862] http://dx.doi.org/10.1080/026990598121936

13. Drake AI, Gray N, Yoder S, Pramuka M, Llewellyn M. Factors predicting return to work following mild traumatic brain injury: A discriminant analysis. J Head Trauma Rehabil. 2000;15(5):1103-12. [PMID:10970931] http://dx.doi.org/10.1097/00001199-200010000-00004

14. Andelic N, Stevens LF, Sigurdardottir S, Arango-Lasprilla JC, Roe C. Associations between disability and employment 1 year after traumatic brain injury in a working age population. Brain Inj. 2012;26(3):261-69.

[PMID:22372413] http://dx.doi.org/10.3109/02699052.2012.654589

15. Taylor BC, Hagel EM, Carlson KF, Cifu DX, Cutting A, Bidelspach DE, Sayer NA. Prevalence and costs of cooccurring traumatic brain injury with and without psychiatric disturbance and pain among Afghanistan and Iraq War Veteran V.A. users. Med Care. 2012;50(4):342-46. [PMID:22228249] http://dx.doi.org/10.1097/MLR.0b013e318245a558

16. Mittenberg W, DiGiulio DV, Perrin S, Bass AE. Symptoms following mild head injury: Expectation as aetiology. J Neurol Neurosurg Psychiatry. 1992;55(3):200-204.

[PMID:1564481]

http://dx.doi.org/10.1136/jnnp.55.3.200

17. Cicerone KD, Kalmar K. Persistent postconcussion syndrome: The structure of subjective complaints after mild traumatic brain injury. J Head Trauma Rehabil. 1995;10(3): $1-17$.

18. James W. The principles of psychology. New York (NY): H. Holt and Company; 1890.

19. Twamley EW, Jeste DV, Bellack AS. A review of cognitive training in schizophrenia. Schizophr Bull. 2003;29(2):359-82. [PMID:14552510] http://dx.doi.org/10.1093/oxfordjournals.schbul.a007011

20. McGurk SR, Twamley EW, Sitzer DI, McHugo GJ, Mueser KT. A meta-analysis of cognitive remediation in schizophrenia. Am J Psychiatry. 2007;164(12):1791-1802. [PMID:18056233] http://dx.doi.org/10.1176/appi.ajp.2007.07060906

21. Wykes T, Huddy V, Cellard C, McGurk SR, Czobor P. A meta-analysis of cognitive remediation for schizophrenia: Methodology and effect sizes. Am J Psychiatry. 2011; 168(5):472-85. [PMID:21406461] http://dx.doi.org/10.1176/appi.ajp.2010.10060855 
22. Sitzer DI, Twamley EW, Jeste DV. Cognitive training in Alzheimer's disease: A meta-analysis of the literature. Acta Psychiatr Scand. 2006;114(2):75-90.

[PMID:16836595]

http://dx.doi.org/10.1111/j.1600-0447.2006.00789.x

23. Carney N, Chesnut RM, Maynard H, Mann NC, Patterson $\mathrm{P}$, Helfand $\mathrm{M}$. Effect of cognitive rehabilitation on outcomes for persons with traumatic brain injury: A systematic review. J Head Trauma Rehabil. 1999;14(3):277-307. [PMID:10381980] http://dx.doi.org/10.1097/00001199-199906000-00008

24. Koehler R, Wilhelm EE, Shoulson I; U.S. Institute of Medicine Committee on Cognitive Rehabilitation Therapy for Traumatic Brain Injury. Cognitive rehabilitation therapy for traumatic brain injury: Evaluating the evidence. Washington (DC): National Academies Press; 2011.

25. Cicerone KD, Langenbahn DM, Braden C, Malec JF, Kalmar K, Fraas M, Felicetti T, Laatsch L, Harley JP, Bergquist T, Azulay J, Cantor J, Ashman T. Evidence-based cognitive rehabilitation: Updated review of the literature from 2003 through 2008. Arch Phys Med Rehabil. 2011;92(4):519-30. [PMID:21440699]

http://dx.doi.org/10.1016/j.apmr.2010.11.015

26. Comper P, Bisschop SM, Carnide N, Tricco A. A systematic review of treatments for mild traumatic brain injury.

Brain Inj. 2005;19(11):863-80. [PMID:16296570]

http://dx.doi.org/10.1080/02699050400025042

27. Tiersky LA, Anselmi V, Johnston MV, Kurtyka J, Roosen E, Schwartz T, Deluca J. A trial of neuropsychologic rehabilitation in mild-spectrum traumatic brain injury. Arch Phys Med Rehabil. 2005;86(8):1565-74. [PMID:16084809]

http://dx.doi.org/10.1016/j.apmr.2005.03.013

28. Management of Concussion/mTBI Working Group. VA/ DoD clinical practice guideline for management of concussion/mild traumatic brain injury. J Rehabil Res Dev. 2009; 46(6):CP1-68. [PMID:20108447]

29. Twamley EW, Vella L, Burton CZ, Heaton RK, Jeste DV. Compensatory cognitive training for psychosis: Effects in a randomized controlled trial. J Clin Psychiatry. 2012;73(9): 1212-19. [PMID:22939029] http://dx.doi.org/10.4088/JCP.12m07686

30. Raskin SA, Buckheit CA, Waxman A. Effect of type of cue, type of response, time delay and two different ongoing tasks on prospective memory functioning after acquired brain injury. Neuropsychol Rehabil. 2012;22(1):40-64. [PMID:22181940] http://dx.doi.org/10.1080/09602011.2011.632908

31. Kreutzer JS, Wehman P, Morton MV, Stonnington HH. Supported employment and compensatory strategies for enhancing vocational outcome following traumatic brain injury. Brain Inj. 1988;2(3):205-23. [PMID:3167277] http://dx.doi.org/10.3109/02699058809150945
32. Wehman P, Kregel J, Keyser-Marcus L, Sherron-Targett P, Campbell L, West M, Cifu DX. Supported employment for persons with traumatic brain injury: A preliminary investigation of long-term follow-up costs and program efficiency. Arch Phys Med Rehabil. 2003;84(2):192-96. [PMID:12601649] http://dx.doi.org/10.1053/apmr.2003.50027

33. Weathers FW, Keane TM, Davidson JR. Clinicianadministered PTSD scale: A review of the first ten years of research. Depress Anxiety. 2001;13(3):132-56. [PMID:11387733] http://dx.doi.org/10.1002/da.1029

34. Wilkinson GS. WRAT-3: Wide Range Achievement Test administration manual. 3rd ed. Wilmington (DE): Wide Range Inc; 1993.

35. Raskin S. Memory for intentions screening test. J Int Neuropsychol Soc. 2004;10(Suppl 1):110.

36. Wechsler D. WAIS-III: Wechsler Adult Intelligence Scale. 3rd ed. San Antonio (TX): Psychological Corp; 1997.

37. Delis DC, et al. CVLT-II: California Verbal Learning Test. 2nd ed. San Antonio (TX): Psychological Corp; 2000.

38. Delis DC, Kramer E, Kaplan JH. Delis-Kaplan Executive Function System: Examiner's manual. San Antonio (TX): Psychological Corp; 2001.

39. Kongs SK. WCST-64: Wisconsin Card Sorting Test-64 card version; Professional manual. Odessa (FL): Psychological Assessment Resources; 2000.

40. Blake DD, Weathers FW, Nagy LM, Kaloupek DG, Gusman FD, Charney DS, Keane TM. The development of a ClinicianAdministered PTSD Scale. J Trauma Stress. 1995;8(1):75-90. [PMID:7712061] http://dx.doi.org/10.1002/jts.2490080106

41. Hamilton M. Development of a rating scale for primary depressive illness. Br J Soc Clin Psychol. 1967;6(4):278-96. [PMID:6080235] http://dx.doi.org/10.1111/j.2044-8260.1967.tb00530.x

42. Lehman AF. A quality of life interview for the chronically mentally ill. Eval Program Plann. 1988;11(1):51-62. http://dx.doi.org/10.1016/0149-7189(88)90033-X

43. Bogdanova Y, Verfaellie M. Cognitive sequelae of blastinduced traumatic brain injury: Recovery and rehabilitation. Neuropsychol Rev. 2012;22(1):4-20. [PMID:22350691] http://dx.doi.org/10.1007/s11065-012-9192-3

44. Vasterling JJ, Brailey K, Proctor SP, Kane R, Heeren T, Franz M. Neuropsychological outcomes of mild traumatic brain injury, post-traumatic stress disorder and depression in Iraq-deployed US Army soldiers. Br J Psychiatry. 2012; 201(3):186-92. [PMID:22743844] http://dx.doi.org/10.1192/bjp.bp.111.096461

Submitted for publication January 23, 2013. Accepted in revised form July 11, 2013. 
TWAMLEY et al. CogSMART for Veterans with TBI

This article and any supplementary material should be cited as follows:

Twamley EW, Jak AJ, Delis DC, Bondi MW, Lohr JB. Cognitive Symptom Management and Rehabilitation Therapy (CogSMART) for Veterans with traumatic brain injury: Pilot randomized controlled trial. J Rehabil Res
Dev. 2014;51(1):59-70.

http://dx.doi.org/10.1682/JRRD.2013.01.0020

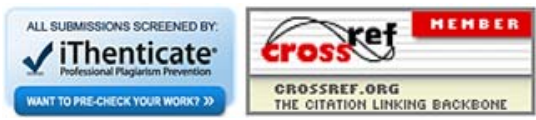


